\title{
Nucleate Pool Boiling on A Plain Surface
}

\author{
Tugba Tetik ${ }^{1,2}$ Ismail Yalcin Uralcan ${ }^{1}$ \\ ${ }^{1}$ Istanbul Technical University, Department of Mechanical Engineering, Istanbul,Turkey \\ ${ }^{2}$ Istanbul Medeniyet University, Department of Mechanical Engineering, Istanbul,Turkey
}

Article History:

Received: 2019/11/07

Accepted: 2019/11/20

Online: 2019/12/31

$\mathrm{N}$ cleate pool boiling of distilled water on a plain copper surface has been investigated experimentally and modeled numerically. In the experimental study, bubble behavior on a single nucleation site was observed using high-speed photography and long-distance microscopy. Diameter for a single bubble growth was determined during the ebullition cycle via recordings. Numerical simulations have been carried out using CLSVOF method using ANSYS 18.2. To verify the simulation, the bubble growth period is compared with the results of the experimental study. Data from the numerical results compare reasonably well with the experimental study.

\section{Keywords:}

Nucleate Pool Boiling, Bubble Growth Rate, High-Speed Photography; CLSVOF
Correspondence to: Tuğba Tetik Istanbul Technical University, Department of Mechanical Engineering, Istanbul, Turkey Tel: +90 2122931300

Fax: +90 2122450795 E-Mail:tetikt@itu.edu.tr

\section{INTRODUCTION}

M ultiphase flows are used in a wide range of industrial applications such as heat exchangers, nuclear reactors, food production, chemical processes, and electronic cooling. It is important to understand, model and simulate multiphase phenomena such as boiling, for cooling technology.

In boiling systems, a large amount of heat is transferred from the surface within small temperature differences between the surface and saturation temperature of the fluid. Although there are many experimental, computational and analytical studies on boiling phenomena, its highly complex physical mechanism hasn't been clarified yet. In recent years, bubbling characteristics have been observed visually on several surface materials with various surface properties such as roughness, cavity size, shape, and spacing.

Zhang and Shoji (2003), made experiments on a silicon surface (15 mm diameter, $0.2 \mathrm{~mm}$ thickness) with distilled water [1]. They worked on cylindrical artificial cavities (10 $\mu \mathrm{m}$ diameter and $80 \mu \mathrm{m}$ depth) arranged as single or twin cavities with 1, 2, 3, 4, 6 and $8 \mathrm{~mm}$ spacing. The bubbling behavior is recorded with a high-speed camera and temperature fluctuations beneath and around the cavities are measured with radiation thermometers. According to their observation and analysis, three significant factors involving nucleation site interactions are determined: hydrodynamic interaction between bubbles; thermal interaction between nucleation sites; horizontal and declining bubble coalescences. Qi and Klausner (2005), studied the activation of cavities with cylindrical, triangular, square and rectangular crosssections, experimentally [2]. They proposed a vapor trapping mechanism for cylindrical cavities. Mchale and Garimella (2010) conducted pool boiling experiments with FC-77 on smooth and rough surfaces [3] The bubble diameter at departure, bubble departure frequency, active nucleation site density, and bubble terminal velocity are measured via monochromatic video recordings obtained using a CCD camera. Interactions between bubbles are characterized. Moita et al. made heat transfer and bubble dynamics analysis on smooth and microstructured surfaces in cooling applications [4]. Their results showed that the heat transfer coefficient for water in the microstructured surface was 10 times higher than the smooth surface.

Boiling phenomena has also been modeled using different numerical schemes. In these models, the liquid-vapor interface is captured with VOF and CLSVOF methods. CLSVOF method was proposed by Bourlioux (1995) [5] and developed by Sussmann\&Puckett (2000) [6]. This method is one of the most widely used interface capturing methods and has been used by many researchers in different fields [7-9]. In CLSVOF method, transport equations are solved both for VOF and level-set fields. VOF provides mass conservation in every mesh, while Level-set defines the interface contour and differentiable fields. Lamas et al. (2012), investigated fluid 
flow around bubbles by analyzing nucleation, growing and detachment processes [10]. In the study, open source software OpenFOAM was used. Depending on the numerical results, a correlation for bubble departure diameter was proposed. Zahedi et al.(2014), simulated bubble formation from an orifice with Fluent 6.3 [11]. In the study, VOF model is used and numerical results were compared with experimental observations and literature results. According to the results, bubble size and detachment time are linear functions of surface tension and decreases with increasing liquid density. Stojanović et al. (2016), studied pool boiling of saturated water under atmospheric conditions, numerically [12]. In the study, density of nucleation sites and bubble residence time on the wall was studied. The influence of these parameters was discussed on pool boiling dynamics.

Although there are many parameters affecting heat transfer in boiling, in the present paper, only bubble growth and departure diameter were studied. Bubble departure diameter and frequency were obtained both experimentally and numerically in the growth period and at departure. The numerical study considers vapor nuclei on a heated wall in a pool of liquid.

\section{METHOD OF ANALYSIS}

Bubble dynamics were observed experimentally and modeled numerically.

\section{Experimental Study}

Experimental setup used for pool boiling tests is shown in Fig. 1. It mainly composed of a test pool which incorporates the boiling surface, the power supply system and measurement instrumentation.

The heater is a cylindrical copper rod $(6 \mathrm{~mm}$ in diameter) which was molded into annular bakelite under high pressure and temperature. The top surface of the copper rod is used as the boiling surface. The smooth surface was produced by mechanical polishing, using sandpapers and alumina particles. The bottom end of the copper rod is screwed into the copper heating block which encompasses the electric heater powered with a $15 \mathrm{~V} \mathrm{x} 200$ A DC supply. Three K-type thermocouples $(0.5$ x $0.8 \mathrm{~mm}$ duplex PFA insulated) were positioned on the axis of the copper rod, below the heating surface, and connected to a KEITHLEY 2750 DMM data acquisition system. Axial temperature distribution along the rod, determined via thermocouple readings, is extrapolated in order to specify the boiling surface temperature. The product of the gradient of the temperature profile and the thermal conductivity of $\mathrm{Cu}$ gave the heat flux at the boiling surface.

Auxiliary heaters, powered with a $35 \mathrm{~V}$ x 20 A DC supply, are placed around the pool in order to maintain satu-

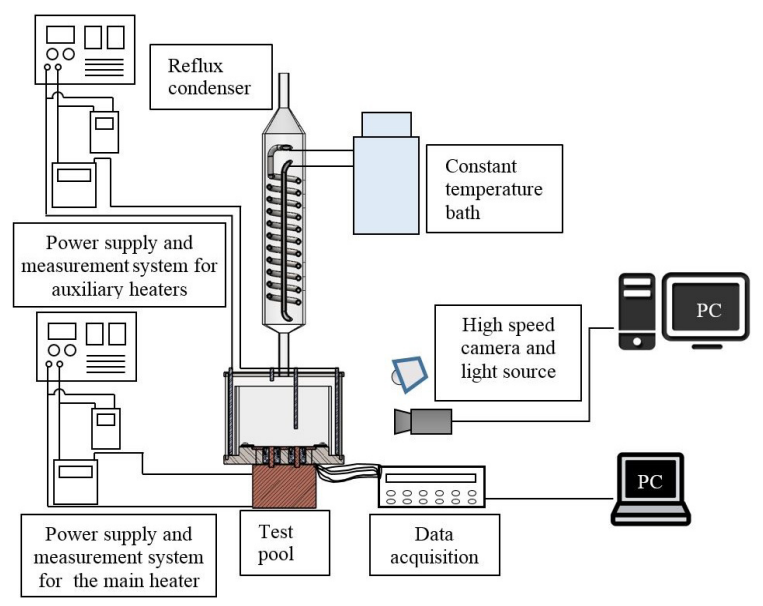

Figure 1. Experimental set-up

ration conditions within the pool. A reflux condenser, equipped with a thermostatic water circulation bath, condenses the vapor formed on the boiling surface and the condensate is returned to the pool.

Prior to each test, the working fluid was boiled by auxiliary heaters to degas it, for at least 2 hours. Afterwards, the DC current to the main heater was adjusted to yield a certain heat flux at the boiling surface. Temperature readings and video recordings were observed until the system attained the steady state and then saved for at least $30 \mathrm{mi}-$ nutes at steady state. All experiments were performed under atmospheric pressure.

The sides of the boiling pool are made of borosilicate glass to visualize the test surface. A high-speed camera (Photron 512-PCI), equipped with a long-distance microscope (Keyence K2 DistaMax) was used to record the images of the growing bubble and the boiling phenomena. Videos are recorded in $4000 \mathrm{fps}$ at $512 \times 256$ resolution.

To determine the bubble growth period, at least thirty bubble cycles were examined and average values were plotted. In order to measure bubble diameter, an image processing code was developed in MATLAB. The bubble images were imported into MATLAB and read as a twodimensional array of color values. After removing noise, Canny method was applied with specified threshold values to detect edges of the bubbles (Fig. 2). The results were given in pixels and then converted to millimeters.
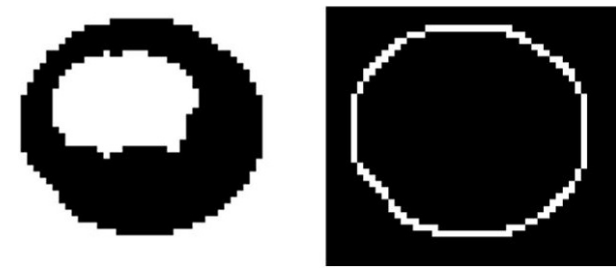

Figure 2. a) Binary image of a bubble b) bubble edge obtained with MATLAB code. 
The boiling curve was plotted with experimental heat flux data and compared to Rohsenow's model. Rohsenow's correlation [13], i.e.

$$
q^{\prime \prime}=\mu_{l} h_{l v}\left[\frac{\left(\rho_{l}-\rho_{v}\right) g}{\sigma}\right]^{1 / 2}\left[\frac{c_{p l}\left(T_{w}-T_{s a t}\right)}{C_{s, l} h_{l v} \operatorname{Pr}_{l}^{n}}\right]^{3}
$$

closely approximates nucleate boiling heat flux for clean surfaces. $\mathrm{C}_{\mathrm{s}, \mathrm{l}}$, and $\mathrm{n}$ are empirical constants which depend on the surface/liquid combination. Recommended values for the $\mathrm{Cu}$-water pair are $\mathrm{C}_{\mathrm{s}, \mathrm{l}}=0.013$ and $\mathrm{n}=1$. [13]

\section{Numerical Simulation Model}

Numerical simulations were carried out for visualizing the behavior of a single bubble during saturated nucleate boiling of water. Pool boiling is modeled by ANSYS Fluent using CLSVOF (Coupled Level-Set and Volume of Fluid) model and numerical results were obtained by using computational fluid dynamics techniques.

Model geometry has been created in Fluent section of ANSYS workbench. Generated geometry was meshed with hexagonal elements. The computational domain is a $2 \mathrm{D}$ axisymmetric rectangular domain having $5 \mathrm{~mm}$ radius and $6 \mathrm{~mm}$ height. The domain consists of solid and fluid regions in accordance with the experimental set-up. The solid region is copper and, water vapor and liquid water form the liquid region. Liquid water was selected as the primary phase and water vapor as the secondary phase.

Transient conservation mass and momentum equations were solved by the pressure implicit splitting operator (PISO) algorithm. Gravitational effects and surface tension were considered.

In the beginning, the pool was filled with saturated stagnant water. The pressure outlet boundary condition was applied to the boundary of fluid at the top of the calculation domain, the backflow temperature was set to the saturation temperature of the water. Both the left and right sides of the pool were given the insulated boundary condition. Initially, a constant temperature boundary condition was applied to the heater. This period is the waiting period and thermal boundary layer forms. When microlayer formed, spherical water vapor was patched in the cavity as the initial bubble. Calculations continued with constant heat flux applied to the heater.
CLSVOF method was used to solve conservation equations for the domain and capture the interface of two-phase fluid.

Bubble growth period predicted from the numerical simulations were compared to experimental results.

\section{RESULTS AND DISCUSSION}

In the experimental work, temperature distribution along the $y$-axis of the copper rod was measured with located thermocouples. Surface temperature is estimated by extrapolating thermocouple readings. With using the temperature gradient through the copper rod, heat flux was calculated as

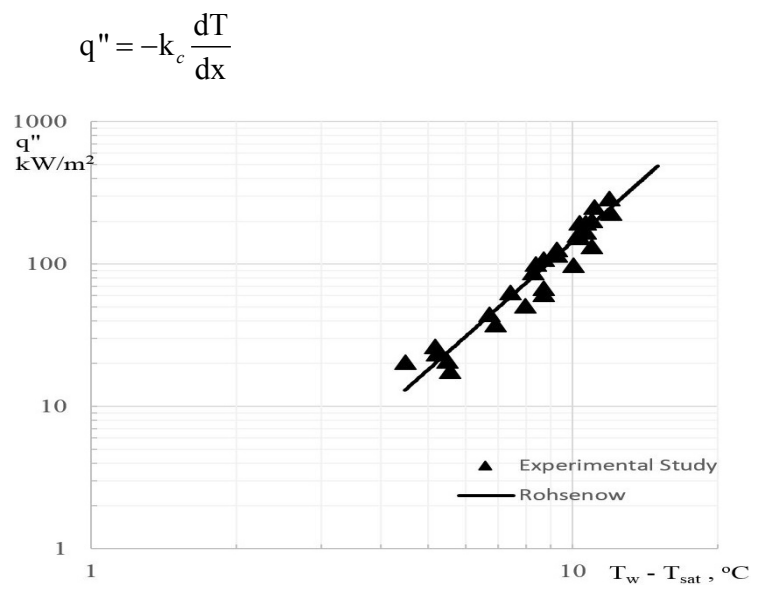

Figure 3 Experimental heat flux data in comparison with Rohsenow equation.

where $\mathrm{k}_{\mathrm{c}}$ is the thermal conductivity of copper.

Fig. 3 depicts the heat flux data versus wall superheat for distilled water on a plain copper surface. In the figure, surface heat flux has been predicted both using Rohsenow's well-known model and Fourier's law.

The boiling curve of Rohsenow's model and experimental heat flux data obtained via thermocouple readings show good agreement as plotted in Fig. 3.

The bubble growth under pool boiling conditions was investigated under constant heat flux condition and bubble diameter was measured via fast camera recordings. Photographic images of phases of bubble formation at a nucleation site for a heat flux of $25 \mathrm{~kW} / \mathrm{m}^{2}$ are shown in Fig. 4.

At low heat fluxes, observed bubbles present a spherical
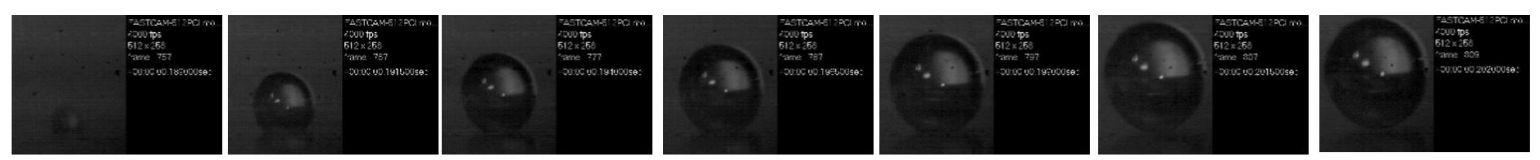

Figure 4 Bubble ebullition cycle for a heat flux $25 \mathrm{~kW} / \mathrm{m}^{2}$ 
shape. Since the theoretical boiling models assume bubbles to be spherical we can compare our experimental results with numerical results. However, at high heat fluxes, bubble shapes differ from the sphere due to fluctuations in the fluid and increasing bubble interactions.

The average bubble departure diameters for various Ja numbers are given in comparison with empirical and semiempirical mathematical models from the literature in Fig. 5. [14-18] Proposed correlations are listed in Table 1. All suggested models have a limited range of application but show a

Table 1. Correlations for bubble departure diameter.

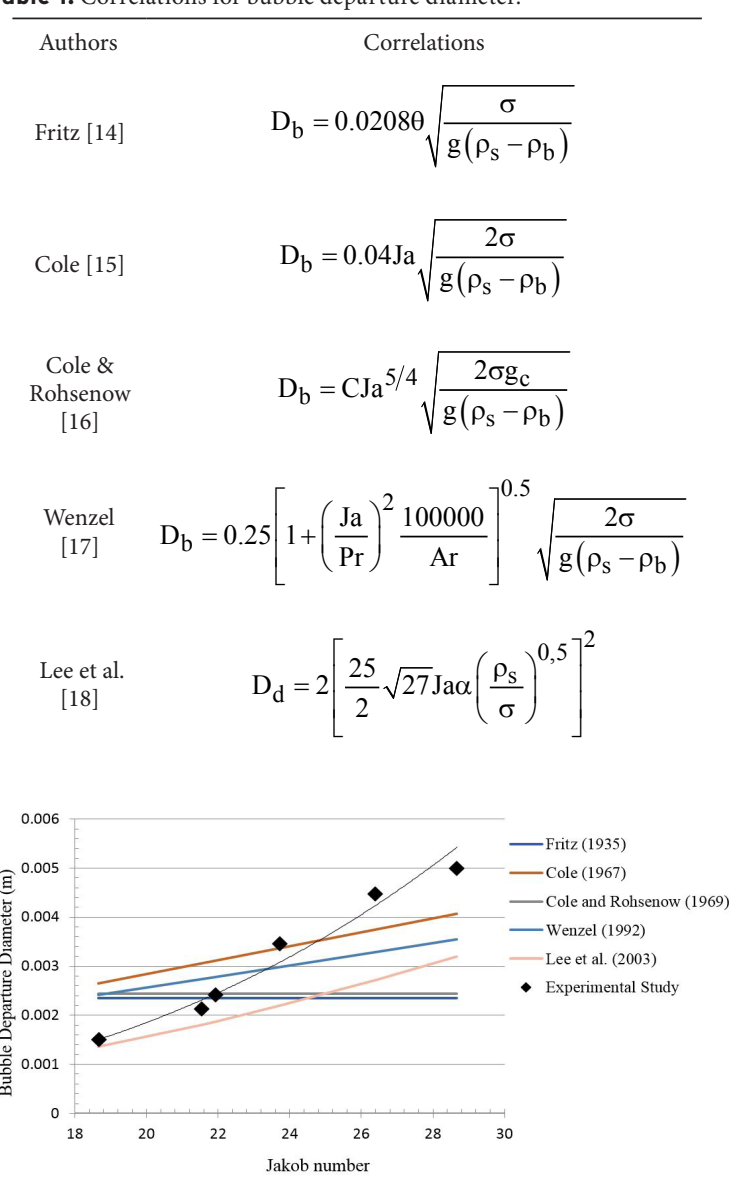

Figure 5. Measured bubble departure diameter at various Ja

Table 2. Correlations for bubble departure diameter and frequency relationship.

\begin{tabular}{lc}
\hline \multicolumn{1}{c}{ Authors } & Correlations \\
Jakob\&Fritz [19] & $f \mathrm{D}_{\mathrm{b}}=0.078$ \\
Zuber [20] & $\mathrm{f} \mathrm{D}_{\mathrm{b}}=0.59\left[\frac{\sigma \mathrm{g}\left(\rho_{\mathrm{l}}-\rho_{\mathrm{v}}\right)}{\rho_{\mathrm{l}}{ }^{2}}\right]^{0.25}$ \\
Cole [21] & $\mathrm{f} \mathrm{D}_{\mathrm{b}}{ }^{1 / 2}=\left[\frac{4 \mathrm{~g}\left(\rho_{\mathrm{l}}-\rho_{\mathrm{v}}\right)}{3 \mathrm{C}_{\mathrm{D}} \rho_{\mathrm{l}}}\right]^{0.5}$
\end{tabular}

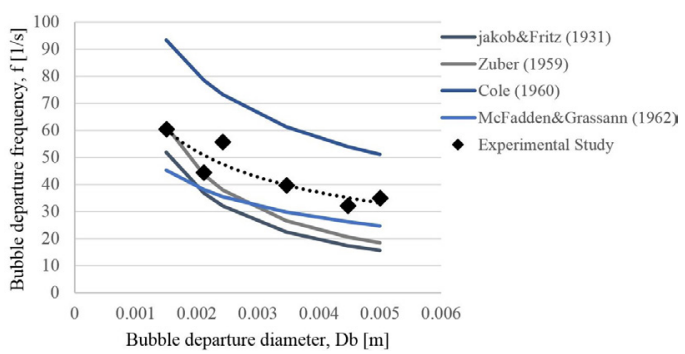

Figure 6. Bubble departure frequency vs departure diameter

similar trend for bubble diameter with increasing Ja.

In the experimental study, each point represents the average value of 30 bubbles. Measured data exhibits a nonlinear relationship and increases with Ja. At higher Ja numbers bubbles merge and vapor departs in a larger size from the surface. Also increasing fluid motion near the surface affects the diameter. A power or exponential model can be suggested when more data are deducted from video recor-

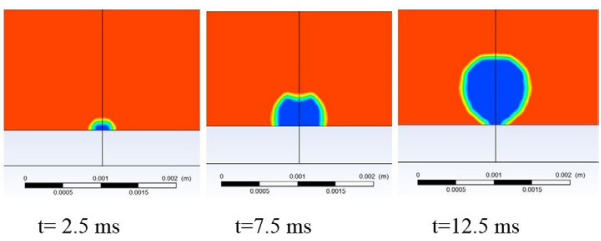

Figure 7. Bubble profile at various time steps

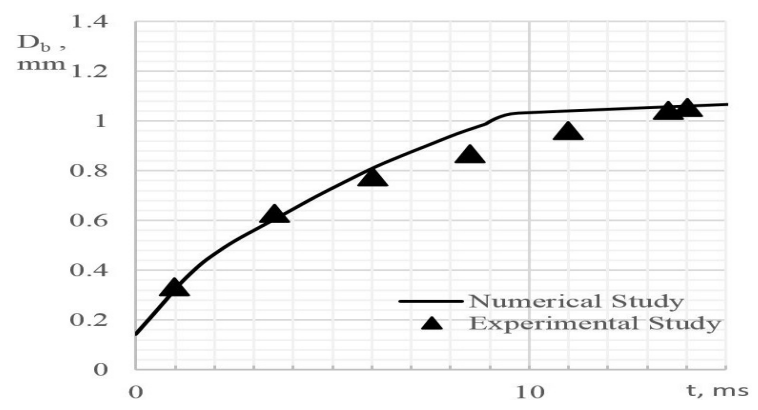

Figure 8. Bubble radius with respect to time. Comparison of experimental and numerical study.

dings in a wider range of Ja number.

Bubble departure frequency versus corresponding bubble departure diameters is given in Fig. 6. Correlations for the determination of departure diameter in pool boiling proposed by researchers are shown in Table 2.

Measured data are compared with theoretical models in the literature. The models predict the experimental trend within an error of $\pm 35 \%$.

Fig. 7 represents the computed bubble growth period on a copper surface, using CLSVOF method. In the analysis, $2 \mathrm{D}$ axisymmetrical simulations were conducted for water at equilibrium with its vapor phase. The computational domain is symmetrical along the $y$-axis.

In order to validate the numerical model, experimental data were used. Time dependence of bubble diameters mea- 
sured from the experimental data are plotted in comparison with obtained data from numerical analyses results. Numerical analyses match well with the experimental results (Fig. 8).

Both from the experimental and numerical results, one can see that at the initial stage bubble grows rapidly due to liquid inertia and the effects of surface tension. In the second stage, the growth is controlled by the heat transfer from liquid to the vapor-liquid interface. Thus, when the evaporation governs the bubble growth, growth rate decreases. The developed numerical model predicts the bubble growth reasonably well with the experimental measurements

\section{CONCLUSION}

In nucleate pool boiling, heat is transferred with bubbles formed on the superheated surface and detached to the bulk liquid. To understand the vapor removal process and determine the heat transfer rate, diameter and the frequency of the vapor bubbles are important parameters.

Nucleate pool boiling experiments at $25 \mathrm{~kW} / \mathrm{m}^{2}$ were conducted. Heat flux and surface temperature measurements have been made for nucleate pool boiling of water on a polished copper surface. Experimental data is found to be in good agreement with Rohsenow's well-known correlation.

Boiling phenomena was visualized with a high-speed camera system and variation of bubble diameter, from initiation to departure, was measured from the acquired images with developed MATLAB code. Video recordings give detailed information on bubble detachment parameters, i.e. the bubble departure diameter and frequency. At higher heat flux, bubble departure diameter is increasing due to bubble coalescence.

Numerical simulation of bubble dynamics was performed for a single nucleation site. The CLSVOF method is applied to simulate bubble behavior in pool boiling conditions. From the numerical simulation, bubble growth rate and departure diameter were observed. In order to validate simulation, computational results were compared with the experimental data.

The bubble growth rate predicted from the numerical simulations agrees well with the experimental observations captured with high-speed photography technique.

\section{ACKNOWLEDGEMENT}

This work is partially supported by "The Office of Scientific Research Projects" at Istanbul Technical University. Project number: 38663

\section{REFERENCES}

1. Zhang L, Shoji M. Nucleation site interaction in pool boiling on the artificial surface. International Journal of Heat and Mass Transfer 46 (2003) 513-522.

2. Qi Y, Klausner JF. Heterogeneous nucleation with artificial cavities. Journal of Heat Transfer 127 (2005) 1189-1196.

3. Mchale JP, Garimella SV. Bubble nucleation characteristics in pool boiling of a wetting liquid on smooth and rough surfaces. International Journal of Multiphase Flow 36 (2010) 249-260.

4. Moita AS, Teodori E, Moreira ALN. Influence of surface topography in the boiling mechanisms. International Journal of Heat and Fluid Flow 52 (2015) 50-63.

5. Bourlioux A. A coupled level-set volume-of-fluid algorithm for tracking material interfaces. Paper presented at 6th International Symposium on Computational Fluid Dynamics. Lake Tahoe, NV, pp. 15-22, 1995.

6. Sussman M, Puckett EG. A Coupled Level Set and Volume-of-Fluid Method for Computing 3D and Axisymmetric Incompressible TwoPhase Flows. Journal of Computational Physics 162 (2000) 301-337.

7. Wang Z, Yang J, Koo B, Stern F. A coupled level set and volume-offluid method for sharp interface simulation of plunging breaking waves. International Journal of Multiphase Flow 35 (2009) 227-246.

8. Son G, Hur N. A coupled level set and volume-of-fluid method for the buoyancy-driven motion of fluid particles. Numerical Heat Transfer, Part B: Fundamentals 42 (2002) 523-542.

9. Arienti M, Sussman M. An embedded level set method for sharpinterface multiphase simulations of Diesel injectors. International Journal of Multiphase Flow 59 (2014) 1-14.

10. Lamas MI, Sáiz Jabardo JM, Arce A, Fariñas P. Numerical analysis of the bubble detachment diameter in nucleate boiling. Journal of Physics: Conference Series, 395 (2012).

11. Zahedi P, Saleh R, Moreno-Atanasio R, Yousefi K. Influence of fluid properties on bubble formation, detachment, rising and collapse; Investigation using volume of fluid method. Korean Journal of Chemical Engineering 31 (2014) 1349-1361.

12. Stojanović A, Stevanović V, Petrović M, Živković D, Stanković B. Numerical study of heat transfer during nucleate pool boiling. Advanced Technologies 5 (2016) 73-80.

13. Rohsenow WM. A Method of correlating heat transfer data for surface boiling of liquids. Technical Report (1951).

14. Fritz W. Berechnung des maximalvolume von dampfblasen. Physikalische Zeitschrift. 36 (1935) 379-388.

15. Cole R. Bubble frequencies and departure volumes at subatmospheric pressures. AIChE Journal 13 (1967) 779-783.

16. Cole R, Rohsenow WM. Correlation of bubble departure diameters for boiling of saturated liquids. Chemical Engineering Progress Symposium Series 65 (1969) 211-213.

17. Wenzel U. Saturated pool boiling and subcooled flow boiling of mixtures at atmospheric pressure. PhD Thesis, The University of Auckland (1992).

18. Lee HC, Oh BD, Bae SW, Kim H. Single bubble growth in saturated pool boiling on a constant wall temperature surface. International Journal of Multiphase Flow 29 (2003) 1857-1874.

19. Jakob M, Fritz W. Versuche über den verdampfungsvorgang. Forsch Ingenieurwes. 2(1931) 435-447.

20. Zuber N. Hydrodynamic aspects of boiling heat transfer. PhD Thesis, University of California (1959).

21. Cole R. A photographic study of pool boiling in the region of the critical heat flux. AIChE Journal 6 (1960) 533-538. 